\title{
Reply to E. Ramos et al
}

\section{Citation}

Hughes, Kevin S. 2018. "Reply to E. Ramos et Al." Journal of Clinical Oncology 36 (5) (February 10): 520-520. doi:10.1200/jco.2017.76.4092.

\section{Published Version}

doi:10.1200/JC0.2017.76.4092

\section{Permanent link}

http://nrs.harvard.edu/urn-3:HUL.InstRepos:36863325

\section{Terms of Use}

This article was downloaded from Harvard University's DASH repository, and is made available under the terms and conditions applicable to Other Posted Material, as set forth at http:// nrs.harvard.edu/urn-3:HUL.InstRepos:dash.current.terms-of-use\#LAA

\section{Share Your Story}

The Harvard community has made this article openly available.

Please share how this access benefits you. Submit a story.

Accessibility 


\section{Reply to E. Ramos et al}

In my editorial in Journal of Clinical Oncology, ${ }^{1}$ I asked about which genetic testing problem we are trying to solve. Is it that "large numbers of women have had undue levels of stress and anxiety, have not received proper informed consent, or have been managed inappropriately because they were tested by someone other than a genetic counselor" or that "hundreds of thousands of mutation carriers are still unaware of their status and will develop cancers that could have been prevented or found earlier"?

Although Ramos and Haidle ${ }^{2}$ call this a false dichotomy, they then proceed to spend the vast majority of their letter trying to prove that physicians are not capable of identifying candidates for testing, providing proper informed consent, ordering the correct test, or managing patients appropriately.

It is time to move on.

I do agree with Ramos and Haidle ${ }^{2}$ that genetic counselors are a vital part of the genetic testing system and can play a crucial role in bringing this critical technology to the entire population. However, we can no longer afford to have genetic counselors serve as the gatekeepers. The genetic testing team must include physicians and other allied health professionals who are currently responsible for identifying high-risk individuals and managing the results of genetic testing after it is completed, yet are often prevented from ordering genetic testing themselves.

Although genetic counselors are experts in risk assessment, they can only assess the risk of someone who is referred to them. If providers do not identify patients as high risk, genetic counselors will not see those patients. By the same token, once a test is completed, the physician must decide how to manage the patient. Although genetic counselors can make suggestions, the physician must determine appropriate options for his or her patient based on the patient's health status and the potential benefits and morbidities of various approaches. Genetic testing is part of the equation but not the only information the physician and patient use to arrive at a management strategy. To say that a physician is capable of providing informed consent as to whether a mutation carrier should have a mastectomy but is not capable of providing informed consent as to whether the patient needs genetic testing in the first place makes little sense.

I think the medical community would agree that a new model is needed, and the model discussed by Ramos and Haidle ${ }^{2}$ makes sense. Physicians, with modest directed education, can handle the vast majority of genetic testing. Having a genetics professional available to help with more difficult problems (on-demand access to genetic counselors) also makes sense. In fact, this system is already in place, as most genetic testing companies have genetic counselors who are available by phone or e-mail at short notice. Local genetic counselors also provide the same service.

This collaborative approach would free up genetic counselors' time (making them available to see complex patients), would speed up the testing process (by avoiding long delays waiting to see a counselor), and would markedly increase the number of patients tested. Rather than patients being told they will see a genetic counselor in a few days, weeks, or months to discuss genetic testing, the test can be initiated immediately at the point of care. Rather than the genetic counselor spending a large amount of time counseling patients who eventually turn out to have a negative test, genetic counselors can concentrate on patients with complex results (eg, those with a variant of unknown significance or a pathogenic variant) and those who need further counseling and education. In addition, this would provide the time needed to undertake the invaluable cascade testing of relatives described by Ramos and Haidle ${ }^{2}$ that seldom happens under the current system.

Genetics can no longer be thought of as the purview of a single specialty but must become an integral component of medical care at all levels. This will not be possible if we require every patient to see a genetic counselor to have testing. Oncologists already order genomic, whole-genome, or whole-exome sequencing of tumors. Pathologists routinely order microsatellite instability and immunohistochemistry testing of colon specimens. Cardiologists order cardiomyopathy testing. Neurologists order genetic testing for neurologic conditions. Most of these tests are ordered by the physician with genetics backup. Oncologists need to be able to order genetic testing for cancer susceptibility for their patients at the point of care. We need to move away from telling physicians that they do not know enough to do genetic testing and move toward telling them what they need to know to do genetic testing well.

\section{Kevin S. Hughes}

Avon Comprehensive Breast Evaluation Center, Massachusetts General Hospital, Bermuda Cancer Genetics and Risk Assessment Clinic, and Harvard Medical School, Boston, MA

\section{AUTHOR'S DISCLOSURES OF POTENTIAL CONFLICTS OF INTEREST}

Disclosures provided by the authors are available with this article at jco.org.

\section{REFERENCES}

1. Hughes KS: Genetic testing: What problem are we trying to solve? J Clin Oncol 35:3789-3791, 2017

2. Ramos E, Larson Haidle J: Genetic testing: Multiple problems to solve. J Clin Oncol doi:10.1200/JCO.2017.76.0942

DOI: https://doi.org/10.1200/JCO.2017.76.4092; published at jco.org on January 2, 2018. 


\section{AUTHOR'S DISCLOSURES OF POTENTIAL CONFLICTS OF INTEREST}

Reply to E. Ramos et al

The following represents disclosure information provided by authors of this manuscript. All relationships are considered compensated. Relationships are self-held unless noted. I = Immediate Family Member, Inst = My Institution. Relationships may not relate to the subject matter of this manuscript. For more information about ASCO's conflict of interest policy, please refer to www.asco.org/rwc or ascopubs.org/jco/site/ifc.

\section{Kevin S. Hughes}

Stock or Other Ownership: Hughes riskApps (CRA Health)

Honoraria: Myriad Genetics, Veritas Genetics, Focal Therapeutics

Consulting or Advisory Role: Health Beacons 